FUTY Journal of the Environment, Vol. 1 No.1, July 2006

(c) School of Environmental Sciences, Federal University of Technology, Yola - Nigeria.. ISSN 1597-8826

\title{
FROM “WASTE TO WANT": REGENERATING ART FROM DISCARDED OBJECTS
}

\author{
Femi Kayode \\ Department Of Industrial Design, \\ Federal University of Technology \\ P.M.B. 704, Akure, Ondo State. \\ E-Mail: Olfok174@Yahoo.Com \\ GSM: 08035827376
}

\begin{abstract}
The paper incites a creative spirit in designers, artists and the art-minded professionals to bestow optimistic look on giving new life to old, discarded objects in their environments. Habitually, the issue of want and waste is part of world's culture. We are in a waste age because as we keep on consuming one thing or the other, so it becomes imperative that wastes are dotted about. Nevertheless, without prudent waste discard practices and creative conversion of dormant materials into substances of benefit to end-users the entire society would be susceptible to environmental epidemics emanating from waste and junk pollution. This is where art and design come in, not just as an agent of waste reduction in a throw-away society like ours, but mainly as a means of giving second life to old, decrepit and rusted or even dead objects lying fallow. The resurgent power of art is defined in body of this paper. For instance, discarded paper materials can be processed and used for modelling in Papier Mache art. Abandon metal scraps, condemned machine components and disposable plastic scraps and found objects are all junks that are very useful in regenerative art. Meanwhile as the primary intention of a designer or an artist is to earn a gainful living from his creative endowment, this paper examines some ways by which discarded objects can be transformed into creative art forms for economic and socio-cultural well-being, irrespective of the seemingly unending economic hardships in the country.
\end{abstract}

\section{INTRODUCTION}

Whatever we see as new today will inevitably become old tomorrow. This insight leads us to the realization that very lofty and profitable ideas of the good old days have become obsolete today. Those one-in-town art styles and fashions of the 60s, 70s and 80s have become outdated in this new millennium and consequently jettisoned. But a solution to these (problems) exists. Virtually all things are recyclable. Furthermore, the redemptive and resurgent power of art is a valuerecovering measure. Abandoned things can metamorphosize into entirely new products in the hand of a creative and resourceful artist or designer. The so-called obsolete ideas can be renewed and made workable again while outdated fashions and styles can be repackaged in a more psychedelic form to become a vogue again. Therefore, the observation that "man is never satisfied with any specific way of doing things, he is never glued to a style, he wants a new thing" (Akinbogun 2000:18) is a truism.

In essence, such adjectives as bad, worn-out, useless, obsolete, unwanted and even, dead characterizing discarded materials are relative in this sense as what is useless 
FUTY Journal of the Environment, Vol. 1 No.1, July 2006

(c) School of Environmental Sciences, Federal University of Technology, Yola - Nigeria.. ISSN 1597-8826

and thrown away in one end may be creatively repackaged to serve a new or different purpose in another end. Logically, throwing away of unwanted things by individuals and corporate bodies, which is now a commonplace continues to become down right obscure by virtue of the on-going global concern for solid waste recycling. The manner in which the so-called "unwanted things" are allowed to rot away without realizing that they could be converted, through recycling, assemblage, regeneration or re-usage is tremendous. Of concern also is the poorly hygienic state of most urban environments in Nigeria, especially Oshodi, Mushin and some parts of Surulere as well as Ajegunle areas of Lagos state because of heaps of abandoned, unconverted garbage. These are clear indications of low level of improvisational and regenerative art awareness in most Nigerians. Consequently, the creative power of art and technology is grossly under-utilized if not completely untapped when discarded objects are allowed to rot and spoil.

Sure, every individual is a consumer of one thing or the other and there has always been something to discard after consumption. Likewise, commercial sectors and factories glut unwanted materials in form of dust, smoke, chemicals, dyes, garbage, refuse, oil trash and junks in certain places. Not withstanding, it is observed that some of these things could still be useful in other places. In organized societies for instance, individual homes, communities or the government earmarks authorized designated locations as dumps for all unwanted materials. In such authorized dumping sites, wastes are expected to be regularly sorted out and the convertible ones processed while the inconvertible ones are incinerated to curb filthiness or eventual epidemic occurrences.

Sadly, various waste disposal sites of offensive odours abound in almost every open space too close to us. More sadly also, heaped rubbish disposed daily bedevils our environments. Aside this, unpatriotic citizens are also noted to have adopted illegal dumping sites like drainages, canals, stream (see plate 1) and the high waters in which solid and chemical wastes are either buried or transported through the water current to innocent shores.

Creating waste dump in the bush may however be advantageous in the sense that when the wastes decompose, they can form a sort of manure useful to the soil (see plate 2). Wastes can also be dumped in land depressions, ditches and trenches to serve as landfill when there is need for filling up.

Indeed, artist/ designer's creative turning of solid wastes to form new products is real wealth apart from being a remarkable contribution toward reducing pollution in the land. Interestingly that waste management mechanism is appropriate for a wasteful society like ours. 
FUTY Journal of the Environment, Vol. 1 No.1, July 2006

(c) School of Environmental Sciences, Federal University of Technology, Yola - Nigeria.. ISSN 1597-8826

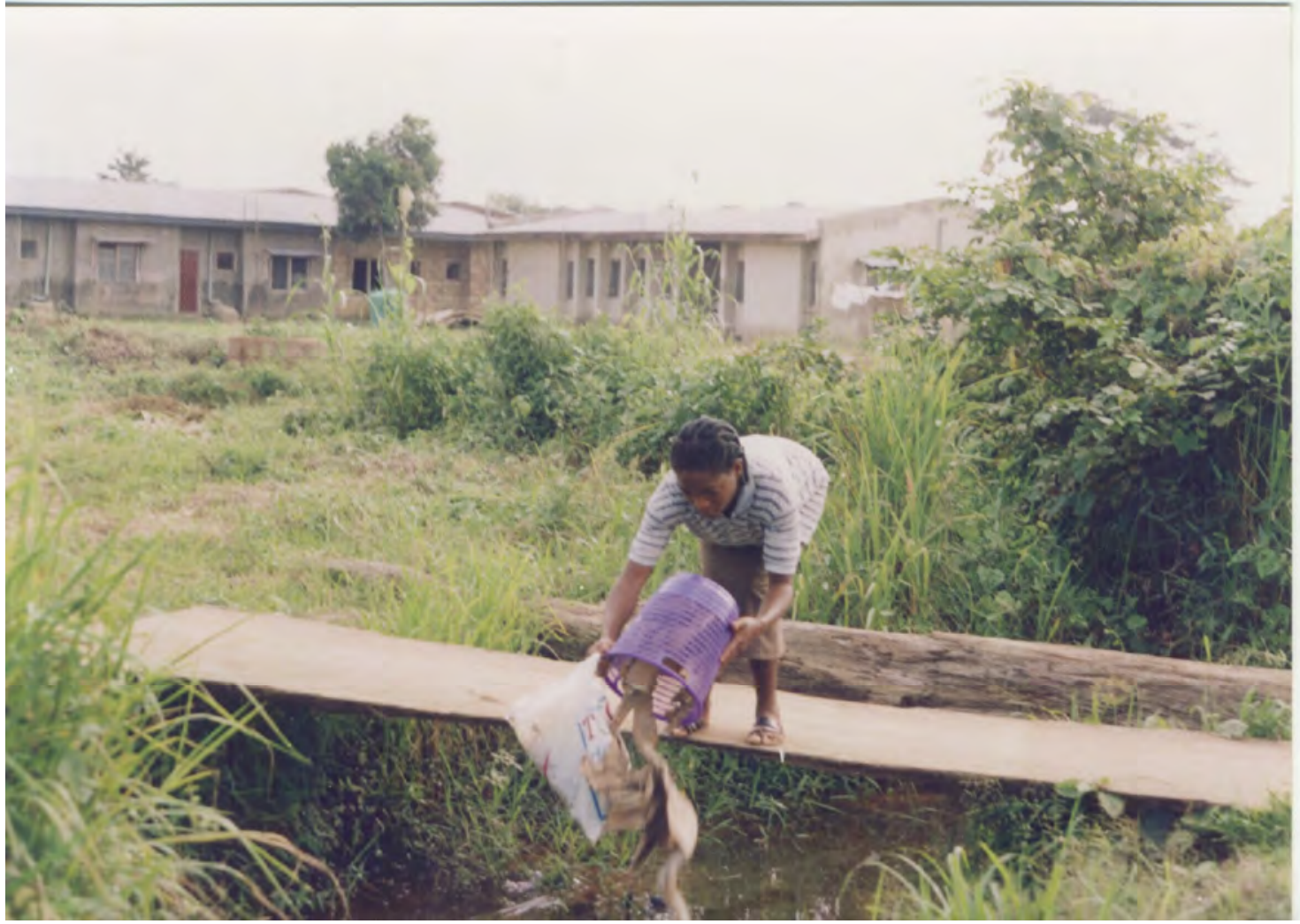

Plate 1: Illegal dumping of refuse inside the drainage

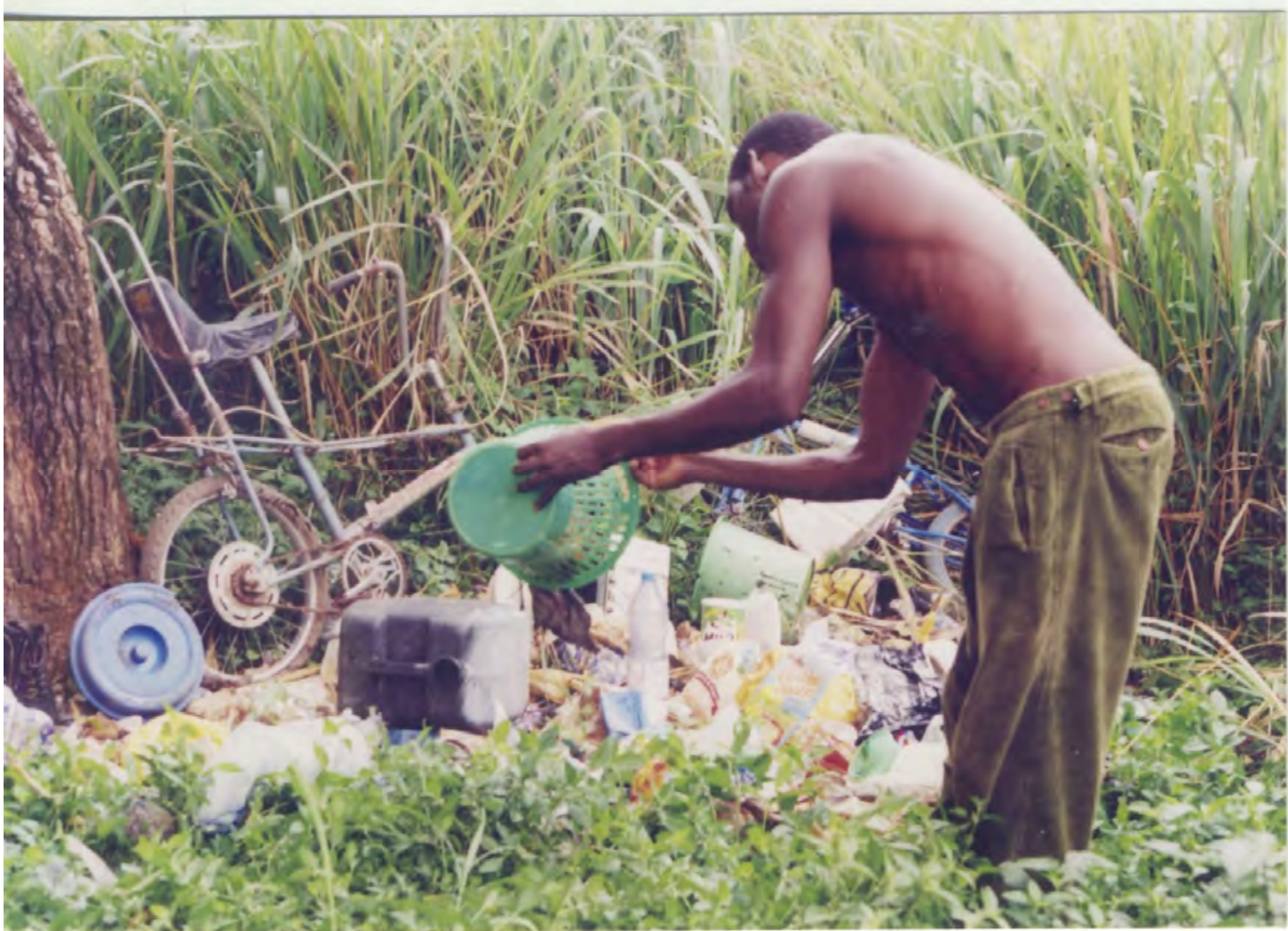

Plate 2: Waste dump in the bush (legal) 
FUTY Journal of the Environment, Vol. 1 No.1, July 2006

(c) School of Environmental Sciences, Federal University of Technology, Yola - Nigeria.. ISSN 1597-8826

\section{Background of Study}

For as many as have experienced flood disaster as a result of blockage of canals and drainages, the wrong waste disposal practice shown in plate 1 of this write-up comes as no surprise. Likewise, that discarded objects are scavenged by some people who have entrepreneurial tendencies for recycling into new products and wealth creation as contained in plates $4,6,7 \mathrm{a}, 7 \mathrm{~b}$ and 8 is not incredible. In this paper the word "waste" is synonymous to the phrase "discarded object", while the word "want" is synonymous to the word "art". What amplifies and publicizes our zeal or ability to transform waste to want is that instinctual spark called creativity. Practical evidences have shown from the works of the great art masters in and outside the Nigerian shores that the power to generate designs from discards lies in the zeal of the artist/designer to keep creativity afloat, and beyond that, make it thrive. By implication, there is need to make clear that art itself is as vital as the creative spark in an individual. Take Leonardo da Vinci for instance, he assembled different machine parts during his time to design and build engineering inventions like the hydraulics. Zammattio (1980: 5) reports that Leonardo's studies of hydraulics and the resistance of structural materials and their application in his design for monumental projects of his day is yet to be surpassed. But creativity imperatives continue to be hampered when poor perception of the waste and the want continually occupies the foreground.

Solid waste conversion and its inventiveness into art forms is environmental management in its own right. Equally, recycling solid wastes into wants to serve in other ends is currently a widespread environmental issue that has whipped up global campaigns and discussions for the well being of the environment as it were and the necessity for prudence in the handling of discarded solid materials. Today, there is a new emphasis on recycling materials, particularly packaging, while design decisions have implications for material used, energy required, pollution generated and waste, (Microsoft Encarta, 2004).

The author of this paper draws an impetus from the earlier analogy made by Kunle Filani who worked on "recycling from waste to wealth'. By waste to wealth Filani (1999:24-27) simply implies recycling wastes to improvise for scarce or unaffordable (imported) art materials at this period of nation's economic depreciation. In developed nations such as America and India very high premium is placed on waste product conversion to wealth for entrepreneurial development in one part and in most part, for the nation's good. For instance, there were such campaign programmes as "waste to energy", "getting cash from trash" and "war against waste" (in America), "converting waste into wealth" (in Canada), "turning waste to wants" (by the Hindus of India), and "Zero waste" initiative (Hausman-Rogers, 2000, Radhakrishnan, 2003, and Dunson, 2005). These programmes were mounted to sensitize cities, neighborhoods and individuals on the need to give a second life to solid waste and discarded materials. To hit the mark, the government of America was so adventurous and resourceful as to encourage among other things, commercial scavenging of dormant materials for onward recycling and commercial rags trading for papermaking and most interestingly, by 1800s most everything had a second life, (Dunson, ibid).

According to Dunson (op cit), through the 20th century "Trash and trash making" became integral to the U.S. economy in a wholly new way: the growth of markets for 
FUTY Journal of the Environment, Vol. 1 No.1, July 2006

(c) School of Environmental Sciences, Federal University of Technology, Yola - Nigeria.. ISSN 1597-8826

new products came to depend in part on the continuous disposal of old things. Instances in America and other parts of the civilized world have been helpful to this research to expose and correct our wrong disposal practices and encourage a culture of 'makeshift', 'homemade' and handmade' in Nigeria. However, under the present discourse, this write-up looks into the various possibilities of creating wealth or other useful things from discarded objects littering our environment. In other words, this write-up is important in the area of convicting discarded scraps; waste matters dotted about and neglected raw materials into useful (decorative or functional) art products that would go for some handsome price.

\section{Methodology}

A methodology designed for any research work gives the various processes, procedures, methods and instrumentalities, by which data are sourced, specified, defined and analyzed (Okoko, 2000). In view of the foregoing, and particularly for the purpose of this research, the methodology of collecting discarded objects is by scavenging and purchase in relevant quarters. Scavenging involves an outreach activity which also involves discretion and selection. During scavenging most wastes collected are found objects (see plate 1). In this regard, the study is directed at target population such as residential and domestic dump sites, artisan and commercial workshops and unrestricted industrial junk yards where discarded objects could be sourced for desired concepts.

\section{Seeking identity and relevance: What is Art?}

The word African art though it exists, is gradually tempering to the rear when we talk about industrial and technological imperatives. Presently, African art should learn to align itself with the schemes of western technologies in order to meet up with the social and economic trends as well as the global educational and political goings-on. Although Art seeks beautiful things, but not only and not merely; art is also power power not only to transform the face of the page, but the quality of our lives (London, 1992), to continue to prosper, art needs professional continuity and societal appreciation and patronage which only adaptation and boost of science and technology can imbue. Clearly, art is heritage but no more completely cultural, it conjures a hybrid of two distinct cultures that is; the western and the indigenous cultures. Lending credence to this allusion, the introduction of the computers and the various digitalized systems, including the robotics are western interventions boosting the relevance of both Applied and Fine Arts to this technological dispensation. For continuing growth and influence, the fabrics of today's art and design, in whatever form, standard or identity should be subjected to technological relevance, it should be what the present and future western technologies could tame and prosper. This seems the only way the art and the artist, the design and the designer can remain in the business. For instance, the applied arts subjects (ceramics, graphics and textiles) are practicable in the industries more directly than the fine art counterpart (sculpture and painting). But two-dimensional models of sculpture and painting could be generated with the aid of the Computer-Aided Design (CAD) for industrial applications - these are applied designs.

The word 'art' is a terminology explained from different views. For instance, Mensah (1986:73) portrays art as "beauty that emanates from skillful ordering of artistic elements, at its command". Whereas Quarcoo (1986:35) remarks that art is an element of culture helping to give us insight into philosophy, social history and the 
FUTY Journal of the Environment, Vol. 1 No.1, July 2006

(c) School of Environmental Sciences, Federal University of Technology, Yola - Nigeria.. ISSN 1597-8826

very cultures of people". Fatuyi (1996:1) views art from a different pedestal as implying artful thinking, artful devices, stratagems, tricks, and much intricate wisdom as contained in the individual person's imagination. In addition to other numerous definitions, the foregoing provide adequate basis for inference to be made in this write-up that, art, as it vividly manifests itself in our society is "the application of practicable skills and attitudes to the conception and production of certain imaginary ideas for a function".

Art is also a means of communication of beautifully thought out ideas in structural and non-structural forms using creative skills. The creative skills in art seems to be surrounded by a veil of mysteries in which case, beholders have always marvel at the changing trends in its functions even when it is just a relaxing pastime. Despite this, art has an age-long value, which is still flourishing with us today. Naturally, as mentioned earlier, over this long period, all the branches of fineart and pseudo-art such as ceramics, graphics, painting, sculpture, textile, and architecture as well as interior decoration, casting and jewelery and the performing arts have become sophisticated. Nwachukwu (2005) opines that developing a new technique for creating something is an art, but once the technique is developed, it becomes public property. Whoever uses this technique thereafter must use it to bring out an experience, which is peculiar to the artist; otherwise the product becomes a craft. Very vividly, every one of the branches of art is tremendously undergoing vast changes in techniques and materials consequent upon the impact of science and technology. This implies that the interdependence between art, science and technology makes art a multi-dimensional and multi-functional phenomenon that will ever be relevant in personal, home and industrial applications.

The innovative boosts that art continues to receive from technology opens up wonderful new possibilities of progress in the workings of media, techniques and materials ranging from simple hand tools to sophisticated Computer Aided Designs (CAD). This is presumably what Galevo (1986:13) refers to as the new identity of art as he makes the following remarks and I quote:

In the space age, more than ever before, art has been seen to serve a great variety of purposes apart from decoration. Art goes into, and comes out of politics, religion, medicine, commerce, science, technology, the economy, education and entertainment.

\section{Discarded objects in our environment}

We all live in a waste age (Dunson, ibid). Nations of the world all share the common craving for technological and industrial viability. Consequently, manufacturings of products that make life easier and environment conducive also contribute to the spoilage of the environment when the wastes generated from packaging and items that have outlived their usefulness are discarded to rotten or constitute filth. This is indeed a case of "the system ruining it self". In view of the foregoing, discarded objects manifest in the following garbs.

Packaging Materials: Everyone has the habit of consumption and at the end of it, has something to call waste. Most consumer products, (electronics, drugs, drinks, canned foods, beverages) including the groceries are characteristically packaged with 
FUTY Journal of the Environment, Vol. 1 No.1, July 2006

(c) School of Environmental Sciences, Federal University of Technology, Yola - Nigeria.. ISSN 1597-8826

artificial product containers made of temporary materials such as paper, nylon and cellophane wrappers, bottles, can and plastic containers. These may eventually end up being thrown away as refuse as shown in plate 3, especially when the main content has been consumed.

Apart from the artificial packaging materials mentioned above, there are natural packaging materials such as shells, peels, bark and pods containing certain agricultural products in them. It is unsightly to note that garbage glut is everywhere as a result of carefree attitude towards proper disposal of unwanted things.

Scraps: Plate 4 shows a collection of metal, aluminum and plastic scraps. Most of the times scraps manifest in the form of junks, discarded as waste chips, worn-out fragments, out-of-date or worthless materials, but they are good materials considered for conversion. Although they may not be wastes in the determinative sense of it, they are dumped to lie perpetually grounded. Scrapping may arise because of spoilage, deadness, worthlessness, or uselessness of an item. Sure, most everything like cracked shoes, leaky pots, crotchety engines, broken umbrellas, disfunctioning clocks, spoilt cycle parts, and condemned wheel are the in-thing when referring to metal scrap assemblage in regenerative art. Infact, the list of designs that can be built up through scrapped materials is endless.

Domestic refuse: These are mixed waste materials, which include dusts, food remnants, rags, bad personal effects, used sanitary wares, unwanted packaging materials, and damaged household utilities garbaged in the surroundings of the home (see plate 5). In this austere time, there is need for consumers to have selective attitude towards discarding of refuse and incineration damaged items that could be usefully recycled to become want or cash. It is equally necessary to keep old possessions in good repair. All these, are sure ways of enhancing sustainable, innovative indigenous technology and of course, a survival strategy for enterprising possibilities. 
FUTY Journal of the Environment, Vol. 1 No.1, July 2006

(c) School of Environmental Sciences, Federal University of Technology, Yola - Nigeria.. ISSN 1597-8826

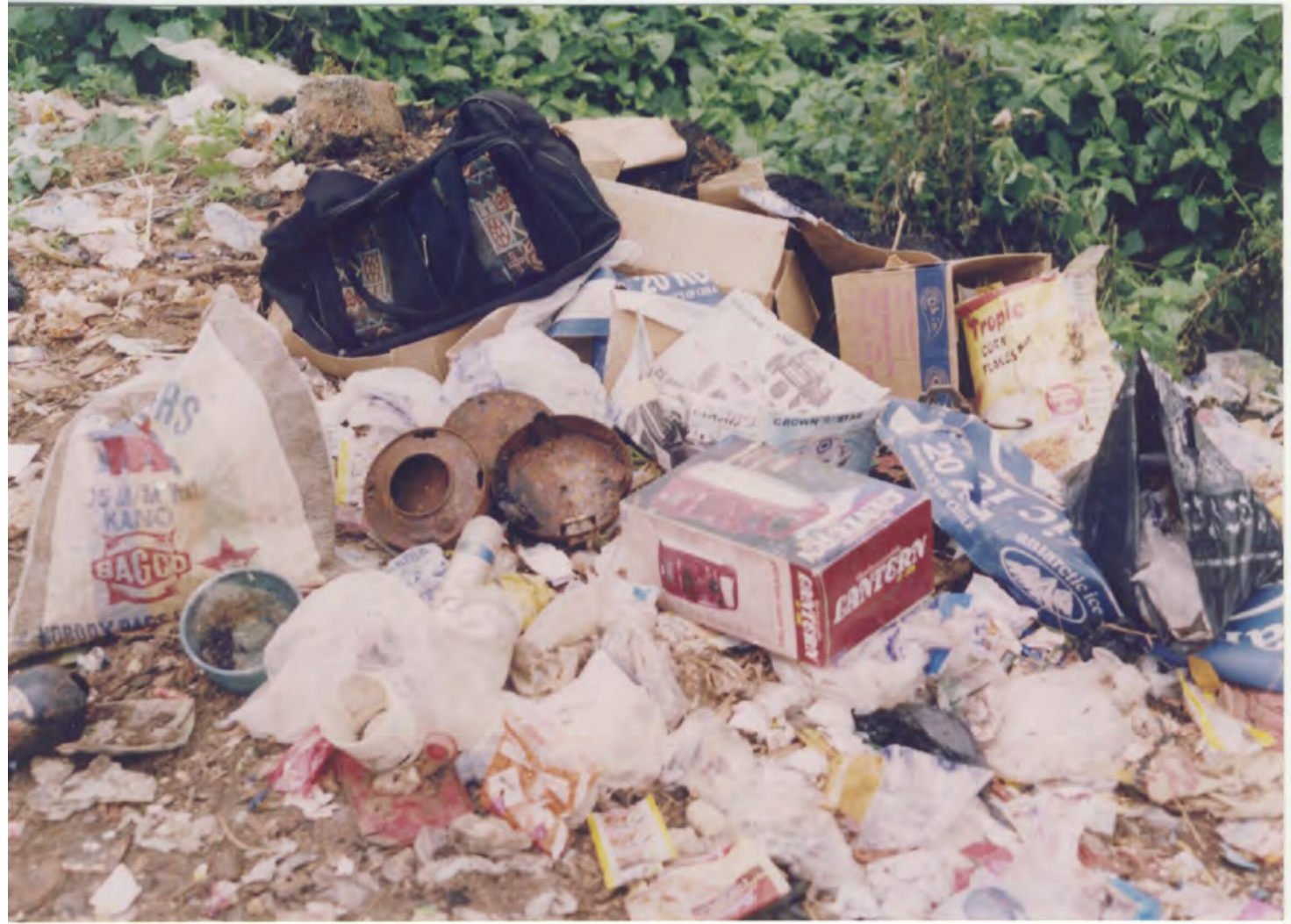

Plate 3: Discarded packaging scraps

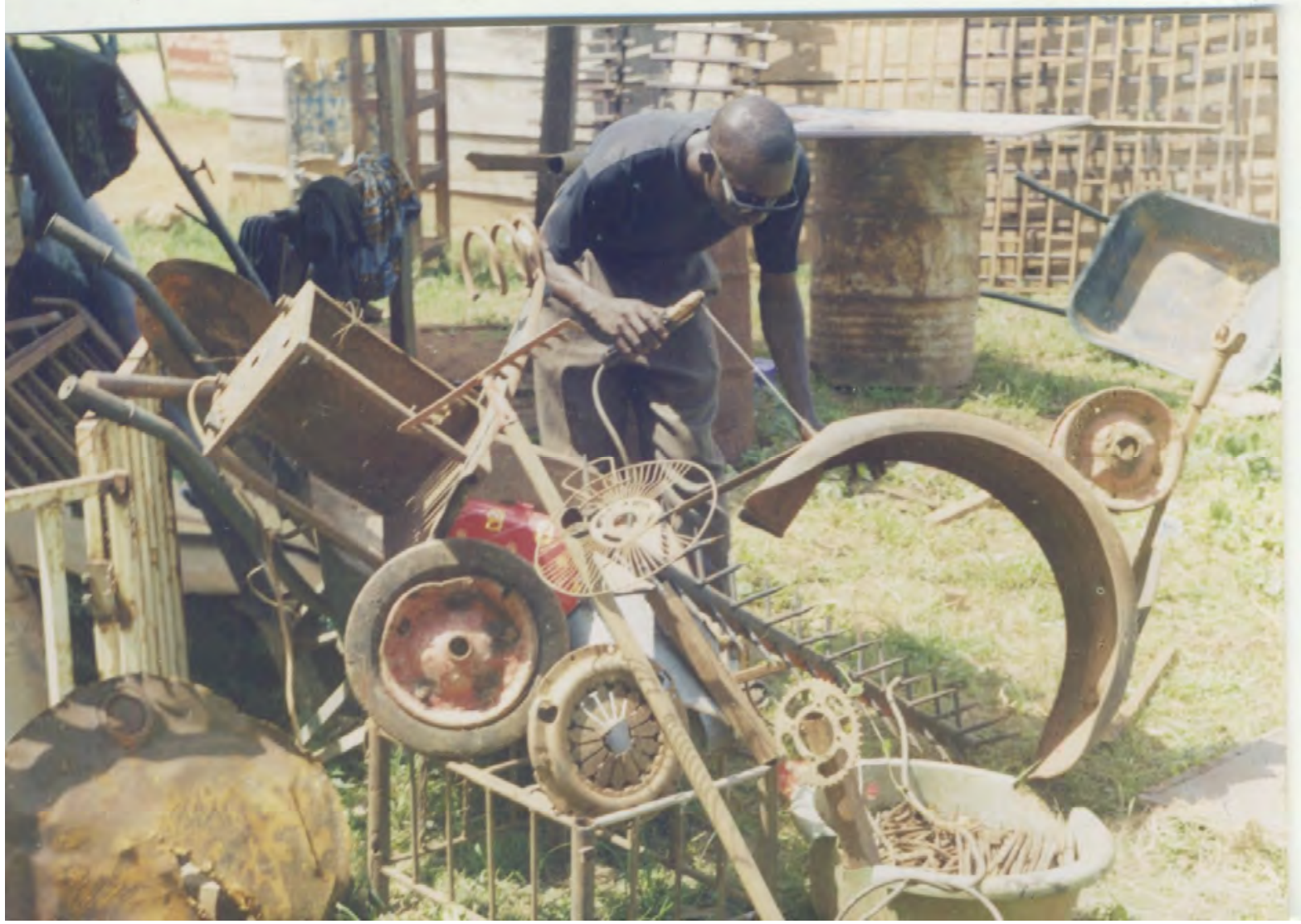

Plate 4: An Assemblage of metal scraps 
FUTY Journal of the Environment, Vol. 1 No.1, July 2006

(c) School of Environmental Sciences, Federal University of Technology, Yola - Nigeria.. ISSN 1597-8826

Industrial Wastes: Generally, all solid and liquid wastes discharged by factories are regarded as industrial wastes. Such wastes may come in the form of chemicals; toxic radio active waste and solid articles like paper, polystyrene materials etc., and unwanted solid raw materials.

\section{Solid Waste scavenging and regeneration}

Waste scavenging initiative is an integral part of waste management and a starting point of recycling or regeneration. Even at that, managing waste is dualistic; as it poses stupendous problems so also it provides big opportunities for turning waste into wealth or want. The problem involves funding for capital machinery and equipments for pollution control, waste reduction, reuse, and recycling. Besides this, Vembar (2005) speaks of Toronto's Solid Waste Management (SWM) scheme thus: "A glance of the financial picture of Metro Toronto's SWM will make one appreciate the truism behind the concepts of wealth from waste". It is hoped that other countries of the world, Nigeria inclusive would borrow a leaf from America especially of her waste scavenging initiatives for wealth creation.

In Nigeria, we are all witnesses to Shell Petroleum Company's contributions to sustainable development. This is evidently an environmental package for practicing waste minimization through planned reduction, reusing and recycling of waste materials generated by the company. In her annual report of the year 2000, titled "People and the Environment", it was reliably learnt that the company generated both biodegradable (food and garden wastes) and non-biodegradable (glass, plastic, scrap metals, cans, paper, toner cartridges, batteries etc) wastes. The former being composted and used as fertilizer while the later handled by recycling vendors in the Warri and Port Harcourt depots of the company. Groneman et al (1986:65) says that reusing materials that otherwise would be thrown away, buried or burned, defines recycling initiatives. Likewise, in the words of Adenle (2002), recycling is changing or transforming used, disposed or abandoned materials into 'New-Old' or 'New-new'.

Inferred from the above positions therefore, waste recycling is seen in two folds first as a mechanism for reducing the accumulation of unwanted items that were discarded and second as a prudent conversion of what is waste in one end to wealth in another end. Of increasing interest therefore, it is a trash transformation and sustainability process that has many levels and complex dimensions especially when it comes to environmental impact and degradation. The complex dimension seems to involve the environment, skill, and the need for regeneration of new things. This is contained in Filani (op cit: 24), which states that:

The word "waste" therefore is a convention term used by one end user, while it becomes another viable raw materials to a new user.

He remarked again that:

Recycling applies to the conversion of a material originally meant for specified use... The interesting thing about using "wastes" is the ability to identify its possible usefulness in meeting other creative ends. 
FUTY Journal of the Environment, Vol. 1 No.1, July 2006

(c) School of Environmental Sciences, Federal University of Technology, Yola - Nigeria.. ISSN 1597-8826

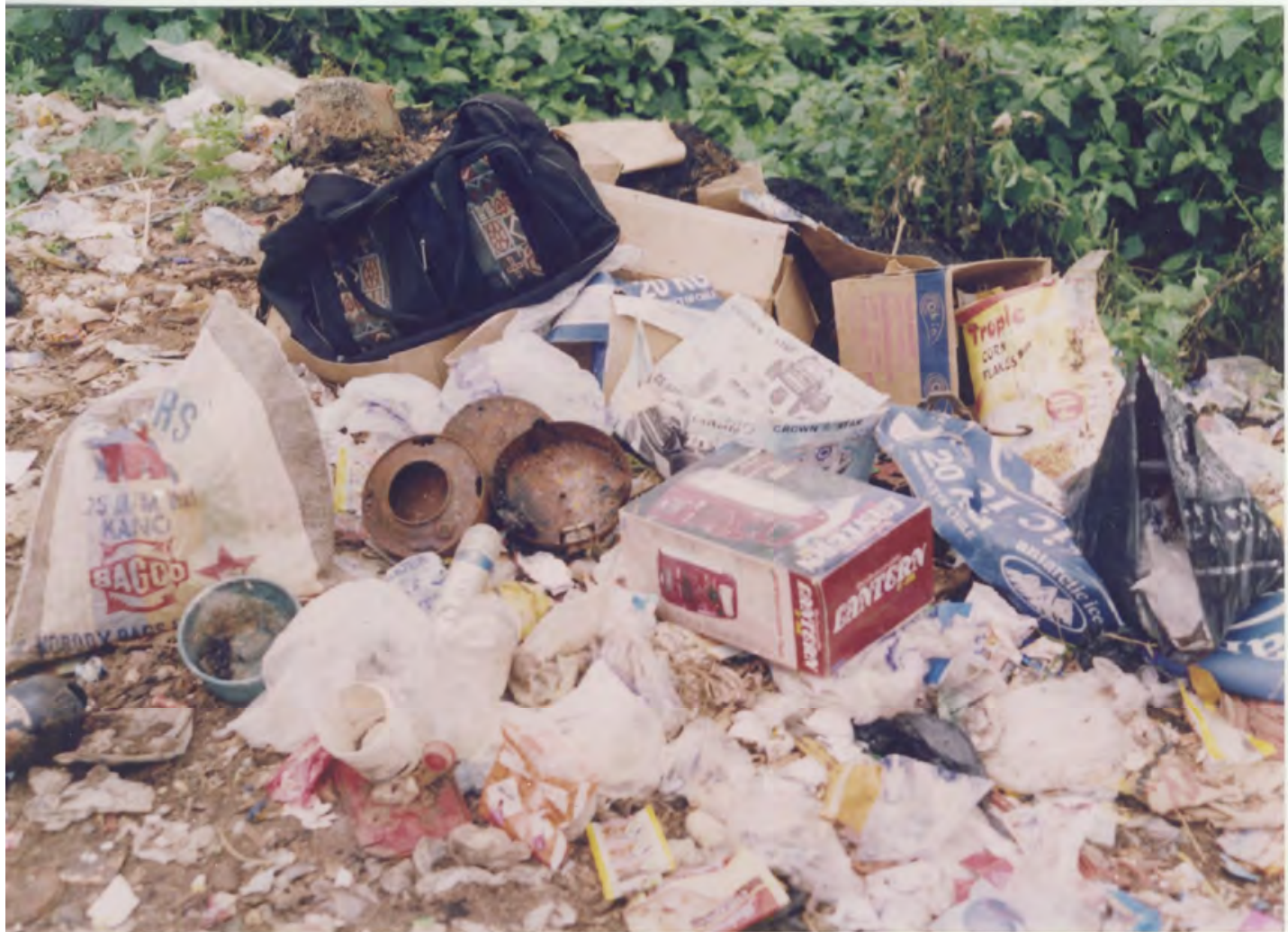

Plate 5: A typical domestic refuse dump

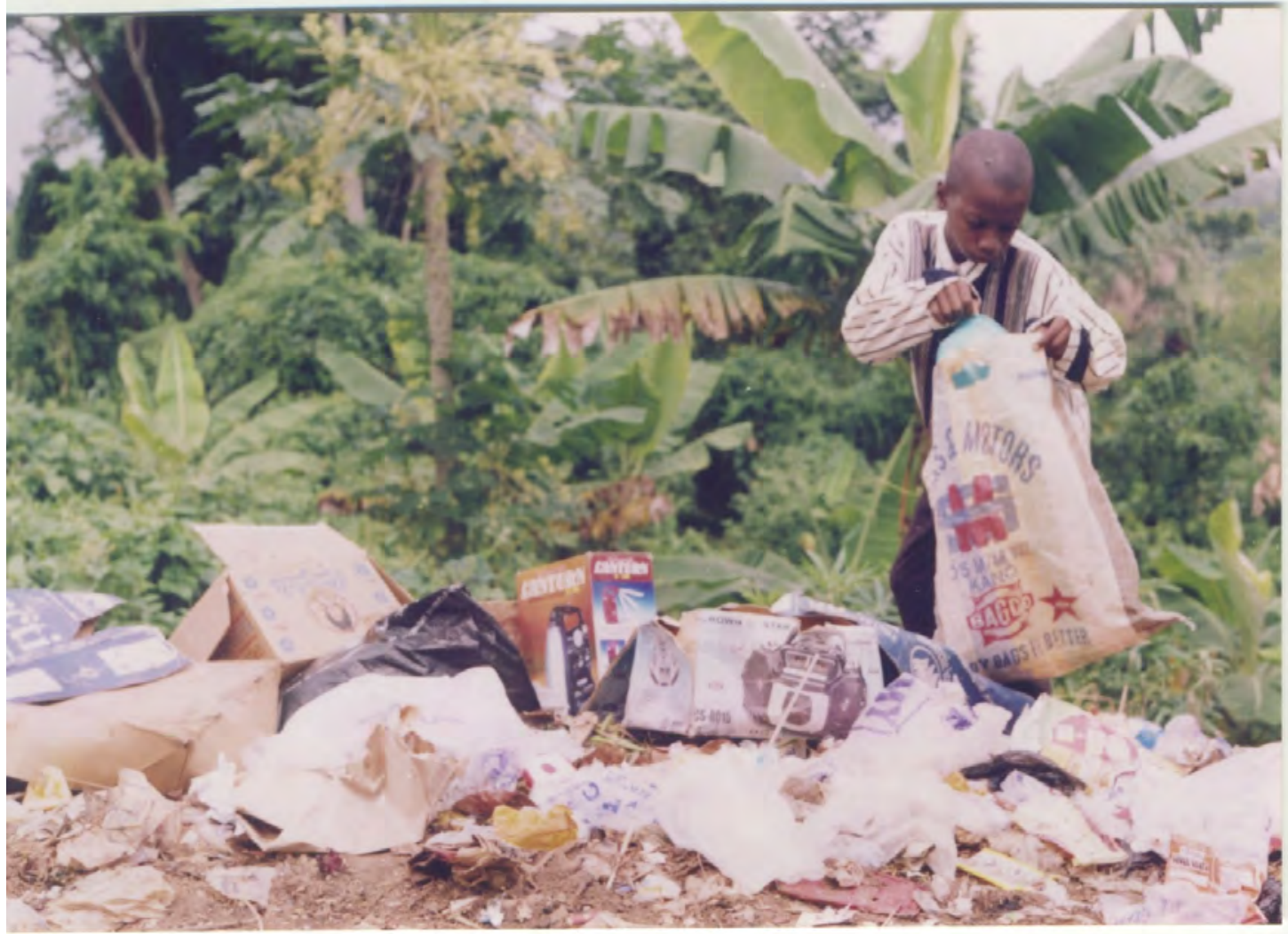

Plate 6: Waste scavenging for recycling. 
FUTY Journal of the Environment, Vol. 1 No.1, July 2006 (c) School of Environmental Sciences, Federal University of Technology, Yola - Nigeria.. ISSN 1597-8826

In essence, iron and steel scraps, aluminum, plastic, paper, cellophane and polystyrene sheets as well as foam are possible substances that can be recycled and reused to produce art directly or to form a new product entirely different from art but with the aid of artistic ingenuity.

\section{Creative transformation of discarded objects into art forms.}

The art of collage: Collage is a derivative of the French word "Coller" - meaning to glue. Gatto et al (1978: 216) defined collage as "a technique in which the artist glues found materials such as coloured paper, cloth and other light weight materials to some type of background". A two-dimensional art, collage is admirable for its variety of sizes, texture, colour and nature of materials arranged together on a background. The nature of materials range from small sticks, scraps of leather, bottle tops, shells, nuts, plastic chips, tiles, and ribbons picked from the dumps. The skilful arrangement of these different materials firmly together to make a pictorial statement is what is called collage. The elements and principles of design, like colour, texture, line, balance, unity, proportion and variety are put to test in producing a good collage work.

Mosaic Art: The definition of mosaic art explains its process. These are crafts in which pictures, patterns are built up from small pieces of various materials such as tiles, pebbles, broken bottles, plastic, and wood chips, beads and other suitable materials glued durably in position with cement on walls or floors. This is what Adhekoyibo (1988:62) describes succinctly as the fixing of square, coloured stones or glasses on a wall to form a picture. In essence, mosaic is a decorative wall craft that is mostly patronized by the rich and the privileged that cherish the value of such art in their exterior and interior.

The art of paper machie: Papier Mache is craft made from paper materials like old newspapers, magazines and cardboards pulped to paste-like solution and starched to be used as a medium for modeling desired objects. Paper machie is a word of French origin referring to pulped, chewed or mashed paper used in modeling light objects. It is a popular art practiced by many cultures of the world such as Japan, India and China. The technique of converting discarded paper rags to paper machie is simple and cheap. Old or tattered paper, preferably newspaper or magazine are torn into small pieces and soaked in a container (bucket or mortar) of considerable quantity of water for some ten to twenty four hours to become marshy. The marshy paper substance is further pounded (with mortar) to become paste-like. The paste-like substance is then starched or glued to achieve a soft and pliable modeling medium for art such as Papier Mache.

The art of metal scrap sculpture: Sculpture generally has often complemented man's efforts in environmental beautification in many cultures over many centuries (Folarin 1993: 125). Metal scrap sculpture is a slight deviation from metal sculpture, which is one of the urban arts that have been used by different civilizations over the years for many purposes. 
FUTY Journal of the Environment, Vol. 1 No.1, July 2006

(c) School of Environmental Sciences, Federal University of Technology, Yola - Nigeria.. ISSN 1597-8826

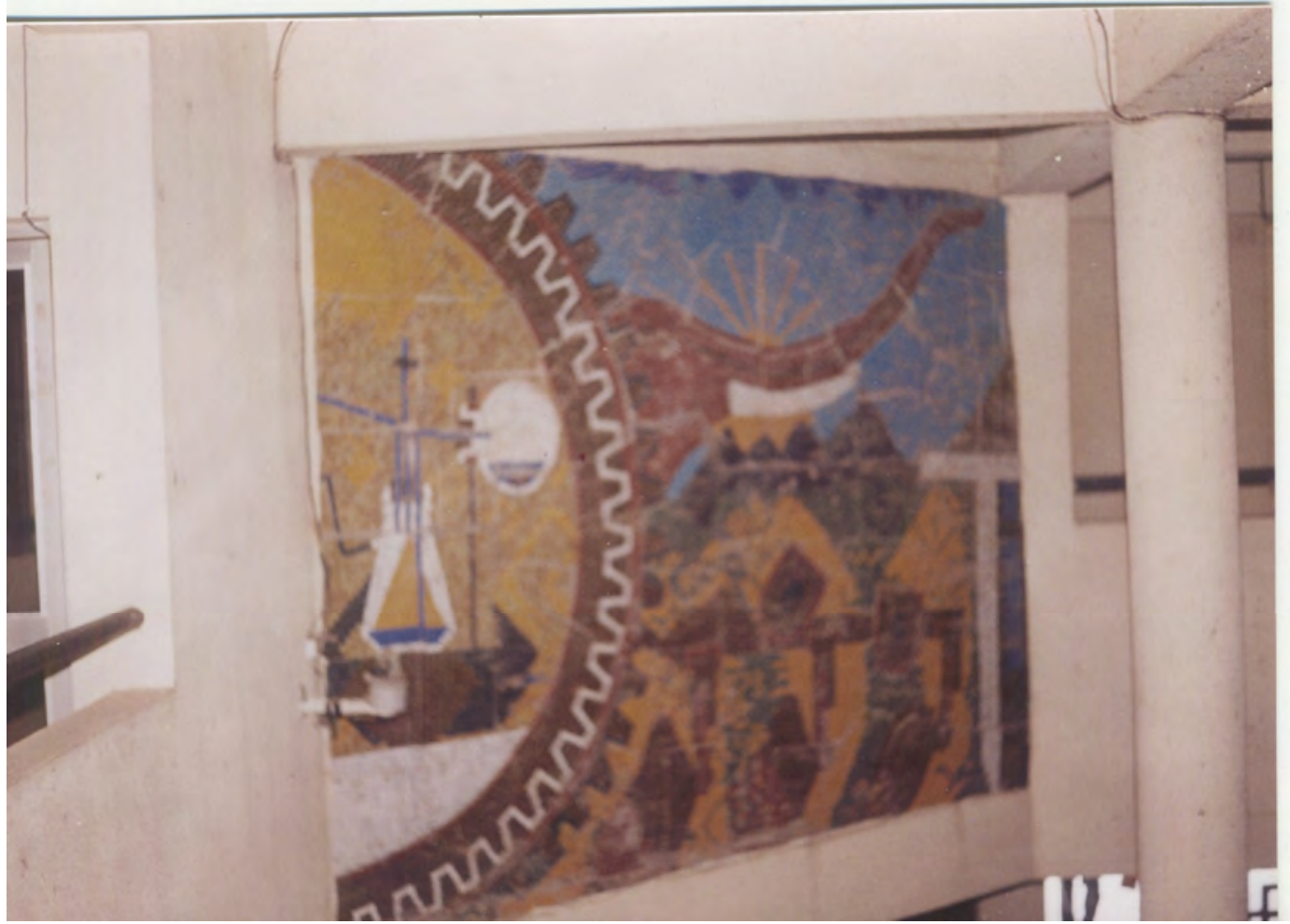

Plate 7: A typical mosaic design depicting science and Technology Courtesy: Federal University of Technology, Akure (Senate Building)

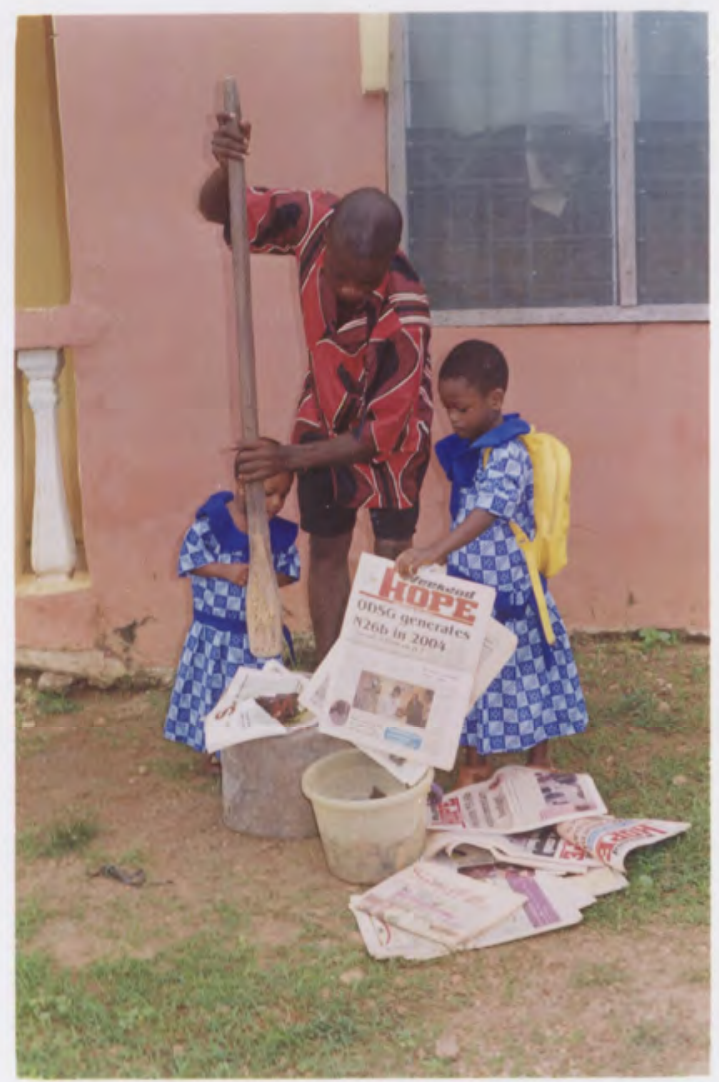

Plate 8: Pounding soaked paper in a mortar to become paste-like (for Papier Mache) 
FUTY Journal of the Environment, Vol. 1 No.1, July 2006

(c) School of Environmental Sciences, Federal University of Technology, Yola - Nigeria.. ISSN 1597-8826

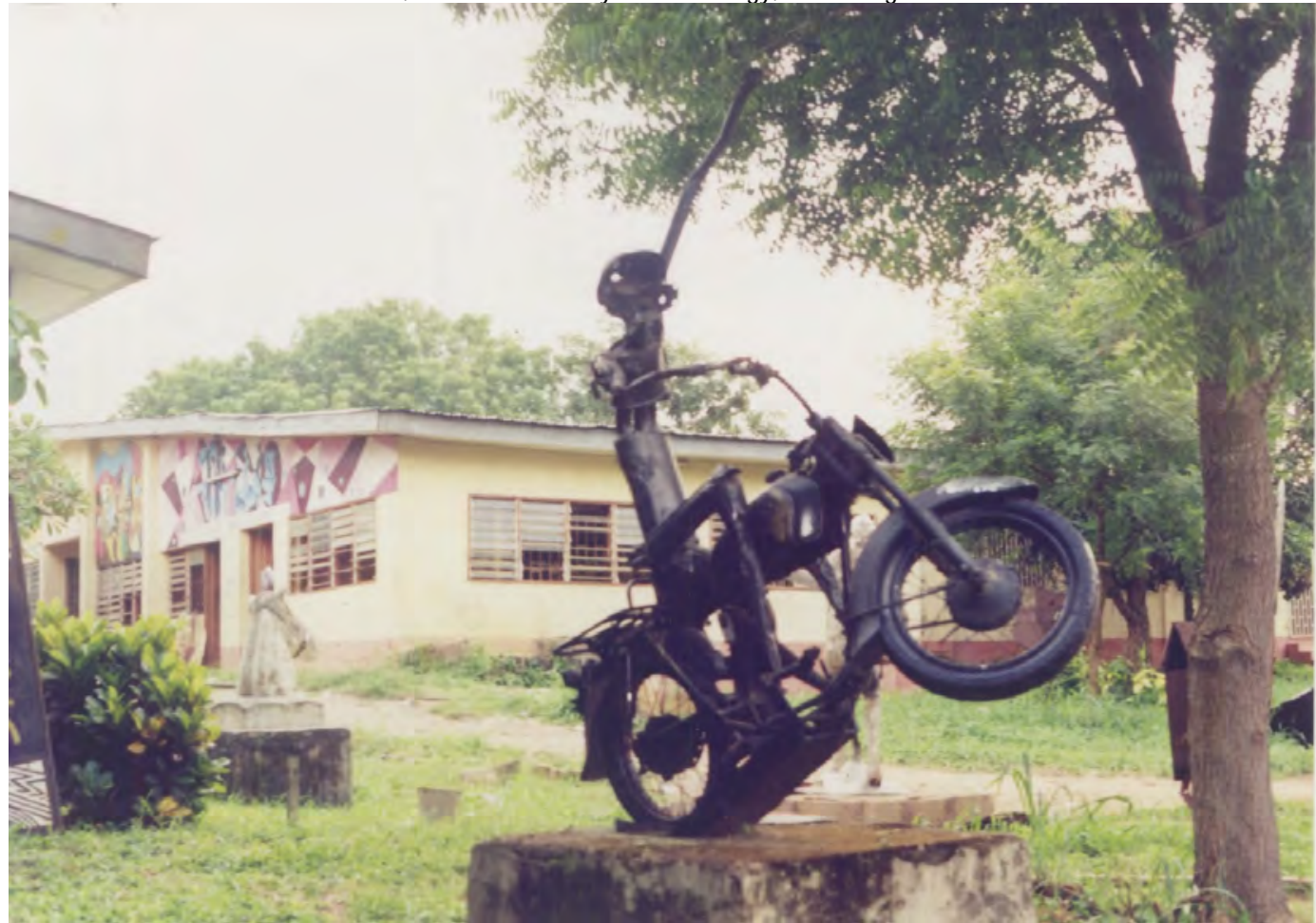

Plate 9a: Metal scrap sculpture of an Okada rider Courtesy: Fine Art Department, FCE., Abeokuta.

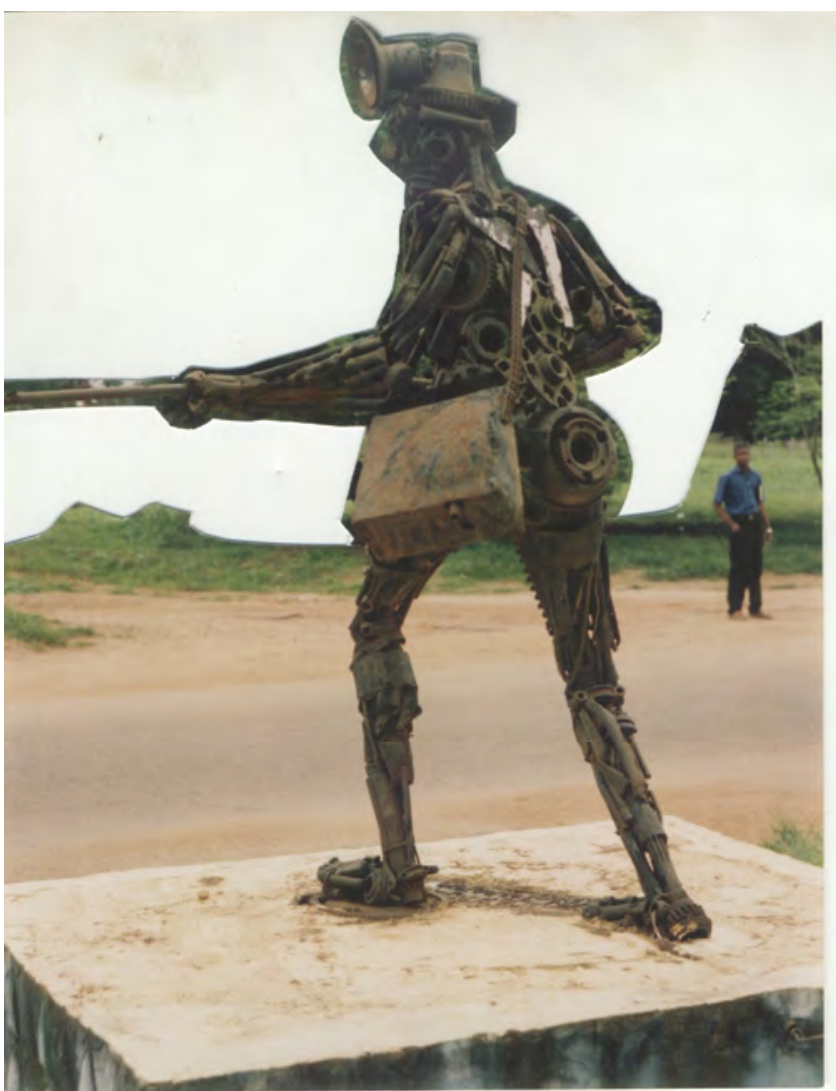

Plate 9b: Metal scrap sculpture of a local hunter Courtesy: Fine Art Department, The Polytechnic Ibadan. 
FUTY Journal of the Environment, Vol. 1 No.1, July 2006

(c) School of Environmental Sciences, Federal University of Technology, Yola - Nigeria.. ISSN 1597-8826

In this type of sculpture (metal scrap) however, different metal scraps are assembled and welded together to construct abstract figure, which will portray a particular three-dimensional form. Commonly, scraps or junks of automobile steel, machine parts, aluminum, and metal sheets and sometimes, other durable non-metal junks are used. Filani (op cit) however makes a remark on the contemporary usage of scraps for metal construction in this way: Many artists are now using junk metals to recreate artistic forms in Nigeria. Various condemned metal parts of machine are creatively recycled by welding them together to model metal sculpture (pp26). Interestingly metal scrap sculptures are actionable caricature of which expression is so gross as to look ludicrous, leaving the beholder to a mental decoding. Also like the real metal sculpture, they are fascinating art pieces traceable to open spaces such as roundabouts, frontages and other public and gardens as shown in plates $7 \mathrm{a}$ and $7 \mathrm{~b}$.

Mixed media painting: It is one of the modern styles of painting, which sometimes bewilders and frustrates artists. This is so because its planning and execution is mostly of combining all sorts of agreeable scraps to compose a pictorial scene. The composition is then face lifted with brilliant colours on either a flat board or a wall. Discarded things like empty cans, saw dust, broken pieces of calabash, glass and plastic, are made to start a new span of life in mixed media painting shown in plate 8. In the statement of Filani (op cit), the word waste is a conventional term used by one end user while it becomes another viable raw materials to a new user (pp24). In addition, empty egg, coconut and seashells as well as strings; feather, cowries, rags and other garbaged trash can be incorporated into a mixed-media painting to make a pictorial statement. The art may look mundane but it is a style of art that is full of evocative meanings to its audience. For instance, the painter of the "Fulani maid girl" in plate 8 went as far as scavenging broken calabashes, discarded waste baskets, plastic bucket cover, flat roofing zinc, wire (for the earrings) beads and rags and colours. These are indeed, things found relevant in the surroundings that best characterize a Fulani maid girl hawking 'Fura de nono' - popular liquid milk among the Fulanis. 
FUTY Journal of the Environment, Vol. 1 No.1, July 2006

(c) School of Environmental Sciences, Federal University of Technology, Yola - Nigeria.. ISSN 1597-8826

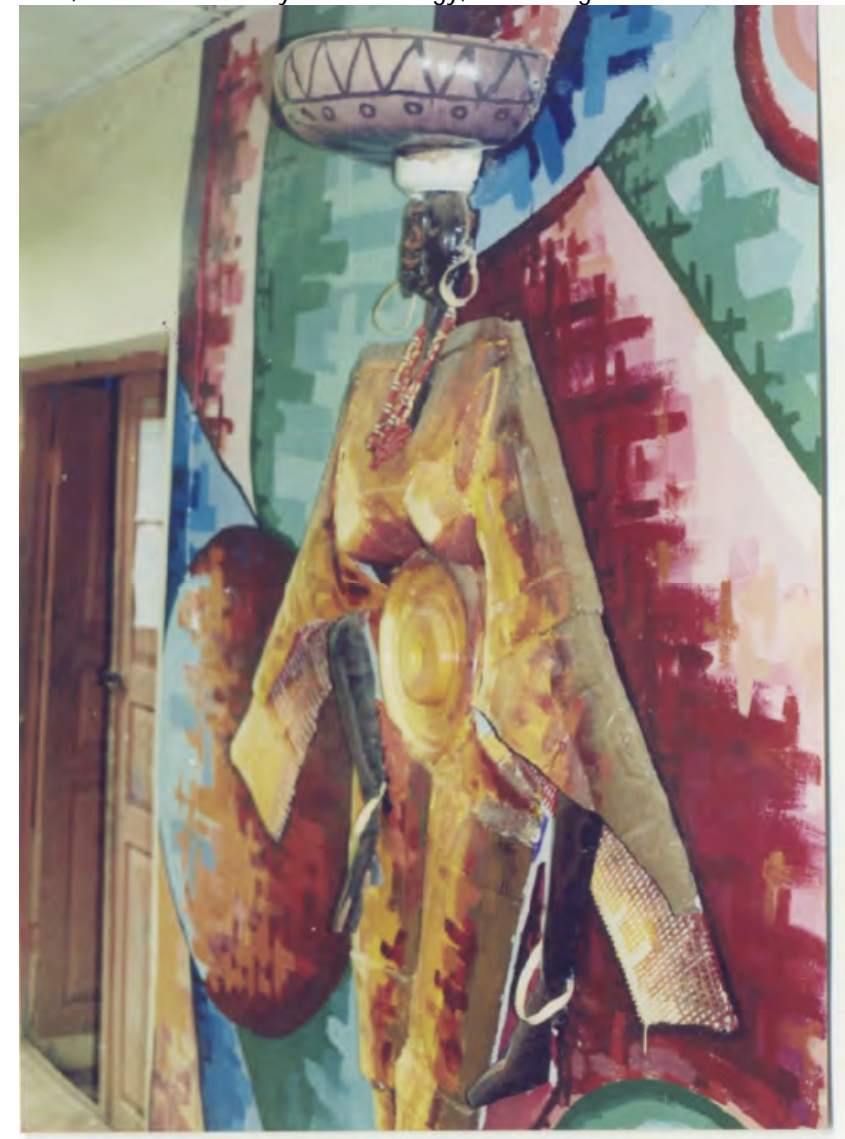

\section{Plate10: Fulani maid girl (Fura de nono) Mixed media painting Courtesy: Fine Art Department, FCE., Abeokuta.}

The Bead making art: Bead making art is another wonderful ornamental dimension. All of organic (ivory, bone and wood), inorganic (precious stones, seashells, glazed and unglazed ceramics) and synthetic (resin) materials can be used. Although these may not be discarded materials, they may be found objects. Today the art of bead-making is regenerating; beautiful beads have been made from discarded broken bottles (glasses) especially among the Nupe tribe of Bida, Niger State, Nigeria.

Ordinarily when a bottle falls to the ground and breaks, the next thing is to pack it up and carefully throw it far away from reach. To a lame man broken bottles are injurious and so, are useless and discardable but to a bead artisan, that is just the beginning of regeneration into beautiful string of beads. The artisan delights in seeing children, men and women of fashion, ceremonial priests, chiefs and the Obas adorned with colourful beads. Nowadays, the use of fashion beads as neck and hand laces as well as earrings and handbags to complement dressing is still in vogue in public ceremonial functions as of old.

To make beads from discarded pieces of glass is an enjoyable art. Fire fanned by a hand-operated bellows to a glowing red state is organized in a (local) furnace and the artisan devises a method of heating the glass by suspension in fire. When the bottle is heated to an extremely molten state, he then holds a rod in his hand, which he 
FUTY Journal of the Environment, Vol. 1 No.1, July 2006

(c) School of Environmental Sciences, Federal University of Technology, Yola - Nigeria.. ISSN 1597-8826

turns deliberately with his fingers to wrap the dropping molten glass being suspended on fire into bead sizes.

\section{Discussion}

The word 'waste' under this discourse is relative. What is waste and discarded at one instance is confirmed in this paper as raw material in another. Therefore, the concept of generating decorative and functional art pieces from dormant items is presently gaining momentum. There is need for improvisation of materials and utilities especially in this period of social and economic adjustment imperatives. Promotion of local self-reliance is of the essence as well. The position of this research is to establish a waste conversion culture in Nigerians through transformation initiatives which yield artistic designs from physical discarded materials. Those who dot wastes about and those who scavenge for thrown away things are both useful in the recycling and regeneration process. It then appears to be a wake-up call for all Nigerians not to totally write off every malfunctioning object or those materials that have been certified dead or redundant at one user's end. One of the ways to rid our environment of solid waste pollution and contamination is to take creative steps of transforming dormant or seemingly useless objects.

Waste materials in the Nigerian example include paper, plastic, nylon sachets, foam, wood and glass packaging materials as shown in plates 1 to 6 in the body of this write-up. For instance abandoned mechanical parts can be assembled and welded together (see plate 4) to construct art decorative pieces as depicted in plates 9 (a), (b).and 10. Fortunately, today more than ever, artists and designers with creative spark are intervening positively in the conversion processes. We should be change makers in this part of the world. By this, we could sustain our lives and the environment and make it dynamic through waste minimization, component repairs, concept revival and reuse.

\section{Conclusion}

We all live in an environment rich in varied discarded objects. The sight of useless wrapping and packaging materials in the form of paper, nylon bags, fruit barks and peels, garden trims as well as domestic refuse constituting ugliness in our neigbourhood is a commonplace. On the other hand, with art creative and resurgent spirit abandoned materials can be picked up and transformed. Regenerating art from waste is favoured by scavenging nowadays. This involves a person or organization sourcing, collecting and marketing a variety of waste materials. It has been said earlier that the Nigerian environment is rich in assorted wastes. So there is no fear, resourceful persons (including poor children) and recycling industries have unlimited scope for self-employment and growth in our society. This is obvious because wastes are so diverse as to cover a broad spectrum of industrial, commercial, institutional, personal, and domestic wastes. Lest we forget, there are various art schools of thought like the western cubism and the Nigerian Osogbo Art School, which have shifted attention away from the conventional art, but are now using worthless objects creatively to express artistic ideas. This is in line with government crusade on economic self-reliance and wealth creation initiatives, which have always emphasized the importance of having a redirection of priority and looking inward to get what we need from what we have. 
FUTY Journal of the Environment, Vol. 1 No.1, July 2006

(c) School of Environmental Sciences, Federal University of Technology, Yola - Nigeria.. ISSN 1597-8826

\section{Recommendations}

The author of this write-up will suggest that research activities should be related to the various present and future needs of our society. This in a way will solve part of our socio-economic problems. So far we can say that art and design education at all levels of school curriculum is inevitable. Art creative experiences therefore offer apt ability to develop our local technological skills, such as resuscitating old wares to become new. The whole idea centred on the intuition to identify possible areas of developing indigenous technologies of Art and Crafts that is capable of changing waste to wealth or waste to want for another end user. This is not only a satisfactory means of self-employment opportunity through the handmade and homemade practices; it is as well a method of waste management in our beloved society.

It is also important to appreciate that waste scavengers are doing so much to rid our society of some filth and in this direction; they should be encouraged by governments and individuals. This by implication means that government should provide steady market for scavenged wastes and recycled products.

There is need to appreciate designers and artists who create art and design works out of improvisation. Considering the technological imperatives, creative end users of discarded objects should enhance their skills and make art and design concepts more relevant to societal needs and the entire national development.

Members of the society, industries and governments need to realize that indiscriminate burning and destruction of every discarded material will not do the nation any good. There is need for individuals and industries to be able to sieve what should be burnt or destroyed and what should not - especially when such objects are not inimical to the creative user's life.

For effective waste minimization, our built environment still needs more of art works generated from discarded wastes. Also in this direction, the government should encourage owners of landed property and estates to make a reflection of one art or the other on every Real Property. This will enhance environmental beautification and aesthetic enhancement of the urbanage.

\section{References}

Adhekoybo, E. (1988): Art Textbook for J unior Secondary Schools. Warri Onukpe Books Ltd.

Adenle, J .O. (2002): "Creative use of solid waste vehicle for National Development". A paper presented at the 4th National Conference of School of Vocational Education, Federal College of Education, Abeokuta.

Akinbogun, T.L. (2000): "Old Wine, New Bottle; A cycle of styles in the Arts". In Journal of Creative Arts, Vol. 1 No 2 pp 81.

Awe, B., (2005), "Nigerian women, the arts and culture: An Overview". In Vanguard, The Arts, Sunday, J anuary 02, 2005 
FUTY Journal of the Environment, Vol. 1 No.1, July 2006

(c) School of Environmental Sciences, Federal University of Technology, Yola - Nigeria.. ISSN 1597-8826

Dunson, C. L., (2005): "Waste and Wealth" in PRIMEDIA Business Magazines and Media Inc. file/ / A: \Waste\%20and\%20Wealth.htm

Fatuyi, R.B. (2000): General Concepts Philosophy and Psychology of Industrial Design, Akure. BSIV Publishers.

Filani, O. (1999): "Trend and Experiments on Improvisation of Art materials in Nigeria: Recycling from waste to wealth." In J ournal of Industrial Design and Technology Vol. 1 No. 1 pp 24-27.

Folarin A. (1993): "Urban Sculpture in Metamorphosis”. In Diversity of Creativity in Nigeria. Ile Ife Department of Fine Arts, O.A.U.

Galevo S.F. (1986): "African Art in Search of New identity". In Arts and Civilisation of Black and African Peoples. Vol. One pp 13.

Gatto, J .A., Albert, W.P. and Selleck J . (1978): Exploring Visual Design, Massachusetts Davis Publications Inc.

Groneman C.H. and Feirer J .L. (1986): General Industrial Education and Technology, Seventh Edition. New York. Mc Graw-Hill Book Company.

Hausman-Rogers, A., (2000), Changing Waste to Wealth, But Whose Expense? Internet Archives, file:/ / C: \DOCUME-1\LOCALS-1\ Temp\LJ FK2J A.htm

London, P., (1992), “Art as Transformation”. In Art Education, Reston, VA: NAEA. Vol. 45, No2., May, pp 8-15

Mensah, A.A. (1986): "African Civilisation and the Performing Arts". In Arts and Civilisation of Black and African Peoples Vol. 1, p. 73.

Okoko, E. E. (2000). Quantitative Technique in Urban Analysis. Ibadan, Kraft Book Limited

Quarcoo, A.K. (1986): “Black Civilization and the Arts”. In Arts and Civilisation of Black and African Peoples Vol. 1, pp. 35.

Radhakrishman, S., (2003), Turning Waste to Wealth, India, The Hindu Business Line,

The Hindu group of Publishers, Monday, October 20, 2003, file:/ / C: DOCUME-1\user1\Temp\6M1VIRAB.htm

Vembar, D., (2005): "Waste to Wealth - Solid Waste Management" file/ / A: \Waste\%20and\%20Wealth-Solid\%20Waste\%20 Management.htm Chennal Interactive Business Service (P) Ltd.

Zammattio, C., (1980), Leonardo The Scientist, London, McGraw-Hill Co Publishers 